\title{
A Novel Radiant Floor System: Detailed Characterization and Comparison with Traditional Radiant Systems
}

Saunak Shukla ${ }^{a}$, Reza Daneshazarian ${ }^{\mathrm{a}}$, Aggrey Mwesigye ${ }^{\mathrm{a}}$, Wey H. Leonga, Seth B. Dworkin*a

${ }^{a}$ Mechanical and Industrial Engineering, Ryerson University, Toronto, Canada

*Corresponding author email: seth.dworkin@ryerson.ca 


\title{
A Novel Radiant Floor System: Detailed Characterization and Comparison with Traditional Radiant Systems
}

\begin{abstract}
Radiant floor systems have the potential to reduce energy consumption and the carbon footprint of buildings. This study analyzed a novel radiant panel configuration comprising a metal plate with small spikes that can be pressed into cement board or wood. The behaviour of this configuration was simulated for different materials for the metal plate, spike dimensions, and varying spacing between spikes. An annual energy simulation model compared the radiant panel configuration with traditional concrete-based system. Simulations were run under heating dominant, cooling dominant, and neutral conditions; significant cost savings and greenhouse gas emission reduction were seen across all scenarios.
\end{abstract}

Keywords: Metal plate with spikes; radiant floor heating and cooling; energy efficiency; thermal comfort; computer simulation; economic optimization

\section{Introduction}

\subsection{Background Information}

\subsubsection{Energy Use in Buildings}

The building sector is responsible for $36 \%$ of total energy consumption and this contributes to $40 \%$ of total Carbon Dioxide $\left(\mathrm{CO}_{2}\right)$ emissions (International Energy Agency 2018). Over the next 40 years, the building sector will grow by nearly 230 billion square meters which is equivalent to adding the floor area of Japan's landmass to the planet every year until 2060 . Hence, there has been a spark of interest globally to reduce the energy consumption of commercial and industrial buildings and residential housing. The combination of strategies such as improving efficiency of heating, ventilation, and air conditioning (HVAC) equipment and reducing the thermal demand of the house by improving envelope conditions, better control, and introducing 
renewable energy technologies could yield significant reduction of greenhouse gas emissions (GHG). The potential for GHG emission reduction, $\mathrm{CO}_{2}$ primarily, is presented in Figure 1.

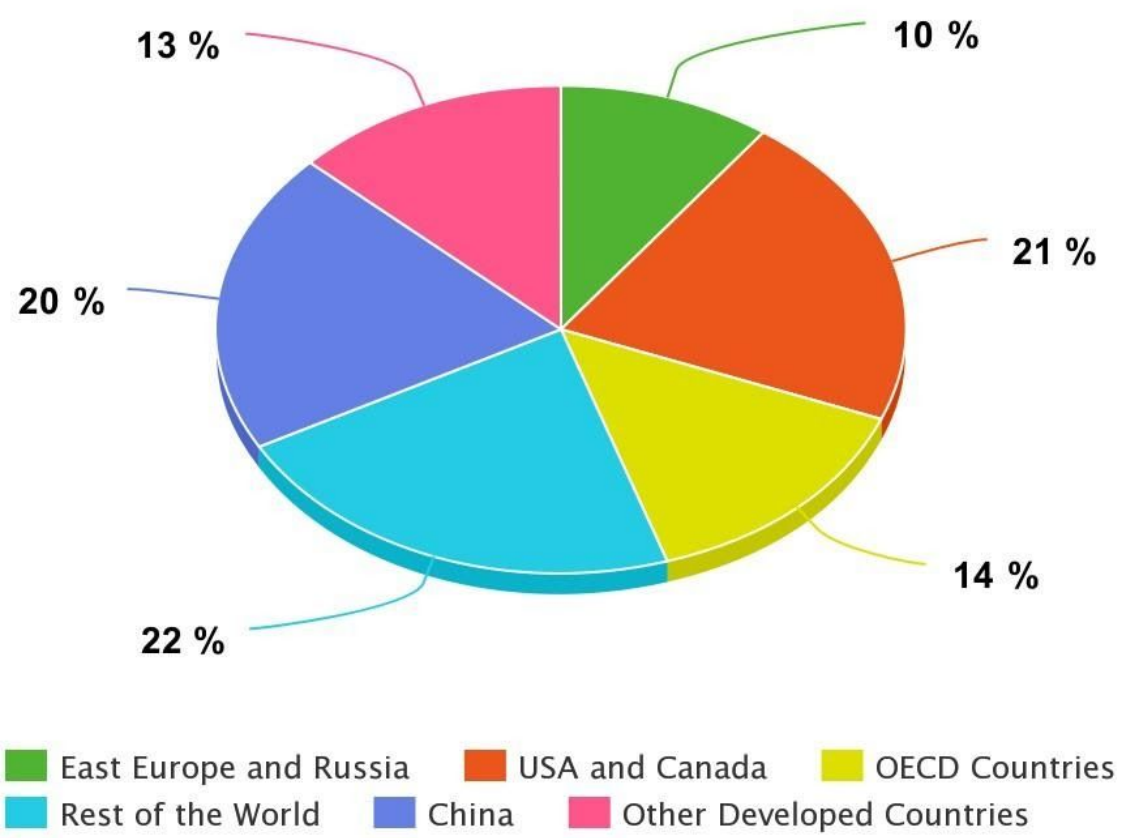

Figure 1. Potential $\mathrm{CO}_{2}$ reductions from the building sector (International Energy Agency 2018)

According to a survey of commercial and institutional energy use, commercial and institutional buildings in Canada represent $26 \%$ of the total energy consumption (National Energy Board 2018). It is important to note that $65 \%$ of the energy consumed in the buildings sector is dedicated to space heating and thus the highest GHG intensity — greenhouse gas emissions per unit floor area $\left(\mathrm{m}^{2}\right)$ - is seen for space heating equipment as well.

At $41.6 \%$ of the total energy consumption of buildings in Canada, the province of Ontario's building sector consumes the highest amount of energy. According to the National Energy Board (NEB) (2017) of Canada, the GHG emission factor for 
electricity and natural gas in the province of Ontario is $40 \mathrm{~g} \mathrm{CO}_{2}$ per $\mathrm{kWh}$ electricity generation and $1860 \mathrm{~g} \mathrm{CO}_{2}$ per $\mathrm{m}^{3}$ of natural gas burned. By significantly improving

radiant floor heating systems, more and more traditional natural gas heating can be offset, leading to reduced GHG emissions. Since buildings are the largest consumer of energy, it is important that space heating systems used in buildings operate in a more economical and sustainable way. This research is in line with Canada Climate Change Action Plan (CCCAP) and the short-term goal of reducing GHG emissions by $15 \%$ below 1990 levels by the year 2020 (Workman 2016).

\subsubsection{Radiant Floor Heating and Cooling Systems}

The Ancient Romans pioneered floor-heating systems; evident from ancient sites known as "hypocausts," the floors were heated by directing exhaust gases from wood fires under raised floors (Woodson 2010). In the early $20^{\text {th }}$ century, when building envelopes were not as airtight as they are now, radiant floor systems were not adopted as much in cold climate countries such as Canada. To compensate for harsh cold climatic conditions, floors had to be heated to uncomfortably high temperatures and thus there was little to no effort made in navigating nuances of space heating systems. However, since the energy crisis of the 1970s, there has been increased focus on implementing building code that fosters 'energy-efficient' building envelopes such that those pertaining to minimizing transmission and ventilation heat losses (Woodson 2010). Radiant floor heating and cooling systems have the potential to offer more benefits to building owners than the widely adopted forced-air convection system. State-of-the-art systems comprise hot water pipes embedded in concrete underneath wood, with a floor surface temperature between $19^{\circ} \mathrm{C}$ and $29^{\circ} \mathrm{C}$ (Woodson 2010 ; "ISO 7730 Standard" 1994; "ANSI/ASHRAE Standard 55-1992 - Thermal Environmental Conditions for Human Occupancy" 1992). They are integral to the sustainable energy 
market as they function well with geothermal, or efficient heat pump systems. They exhibit quiet operation, minimal airborne dust production, furniture space savings, and simultaneously optimize comfort and energy savings (“EN 1264: Floor Heating Systems and Components. European Committee for Standardization" 1994; Olesen 2002).

The ideal heating curve starts at the lowest temperature at the head and increases towards the feet (Olesen 2002). Radiant floor systems follow the same pattern. This demonstrates enhancement in thermal comfort conditions and it is shown in Figure 2.

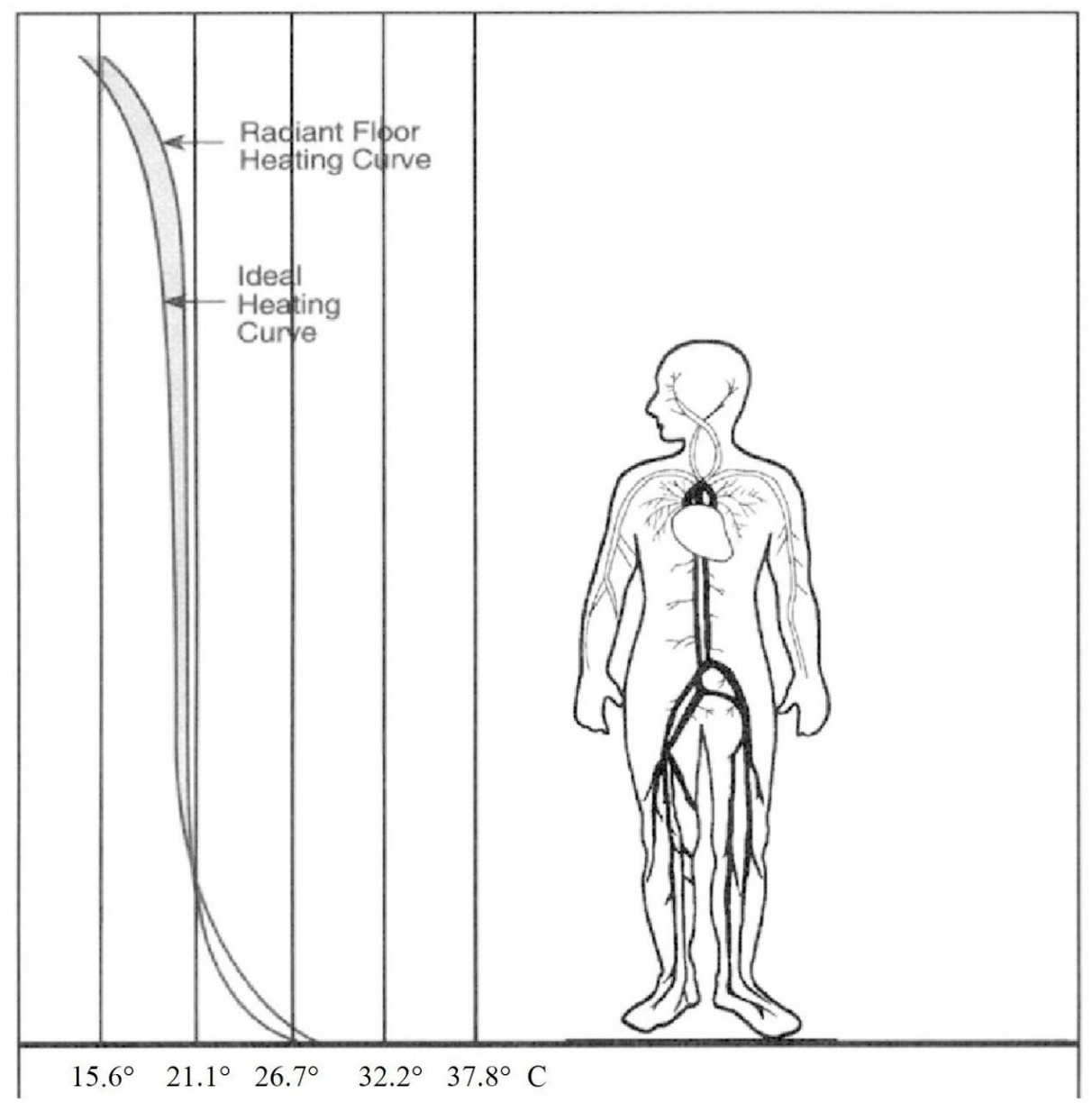

Figure 2. Ideal heating curve and radiant floor heating curve (Olesen 2002) 
Radiant floor cooling systems emerged later than floor heating systems, having first been introduced in dry climates of Europe in the mid- $20^{\text {th }}$ century. They were first employed in the Copenhagen Opera House where outdoor conditions are relatively dry and cool and the floor cooling system's sole purpose is to remove solar heat gain by circulating water at $15-18^{\circ} \mathrm{C}($ Olesen 2008$)$.

The main challenge of radiant floor systems, however, is that they are expensive to construct and install. Furthermore, due to the insulating characteristics of many floor materials (e.g. wood), there is potential to improve energy transfer with advanced system design. Also, they cannot be easily retrofitted and the tendency of concrete to hold heat makes them less responsive to fluctuations in thermal loads (Zhang and Cao 2018).

Since their introduction, a number of studies have considered different variations of radiant floor heating and cooling systems. A review of related studies is presented in the following section.

\subsection{Motivation and Problem Statement}

Different variations of radiant floor heating systems can be found in the literature, each having their own advantages and disadvantages. A study conducted by Olesen et al. (1980) is one of the oldest and most comprehensive studies on thermal comfort of radiant and all-air space heating systems. This was an experimental study that analyzed different space heating systems: radiators, high and moderate temperature; air-distribution, with different diffusor positions; radiant heating, ceiling and floor; and convector. Through different thermal comfort parameters such as vertical air temperature difference, radiant asymmetry, cold draft, and floor surface temperature, the study determined that floor radiant heating systems yielded optimal thermal comfort conditions. Izquierdo and Agustin-Camacho (2015) considered micro photovoltaic-heat 
pump systems in conjunction with radiant floor heating systems. Zhou and He (2015) demonstrated an improvement in thermal performance and comfort of a radiant floor heating system with different heat storage materials; however, they pointed out that the charging and discharging process time is longer with using heat storage materials, rendering them less responsive to rapid fluctuations in thermal loads. Most well-researched radiant floor heating systems fall in the following categories: heavypipes laid out in the concrete layer of the construction or lightweight- pipes placed in aluminum foil (Zhang, Cai, and Wang 2013). Also, numerous studies (Zhang, Cai, and Wang 2013; Ghaddar, Salam, and Ghali 2006; Sakoi et al. 2007) have been performed to demonstrate thermal comfort achieved by radiant floor systems; they show that the temperature distribution is uniform and maintains thermal comfort conditions prescribed by the American Society of Heating, Refrigerating, and Air-Conditioning Engineers (ASHRAE).

Radiant floor cooling systems have been an economically viable option for large space buildings such as airports, convention centers, atria, and entrance halls (Zhao, Liu, and Jiang 2016). This is primarily because, as identified through experimental analyses of multiple studies, the indoor thermal environment in these spaces possess high-intensity solar radiation and high temperature internal wall surfaces (Zhao, Liu, and Jiang 2013; Olesen 1997). For large space buildings whose envelopes are mainly composed of glass facades and skylights, floor cooling is an effective means of removing sensible heat because of direct absorption of solar radiation and long wave radiant heat exchange with a building envelope (Zhao, Liu, and Jiang 2016). Research conducted at Lawrence Berkeley National Laboratory concluded that radiant panel cooling used less than $5 \%$ of the otherwise necessary fan energy to remove a given amount of indoor sensible heat (Feustel and Stetiu 1995). Also, on average, it has the 
potential of saving $30 \%$ of the overall cooling energy in applications across a range of representative climates in North America (Simmonds et al. 2000; Feustel and Stetiu 1995).

There has been little to no research performed on retrofitted radiant floor panel configurations that optimize thermal comfort and save energy, all while operating within $19^{\circ} \mathrm{C}$ to $29^{\circ} \mathrm{C}$ floor surface temperature ranges and minimizing the risk of condensation (Woodson 2010). This study is novel and aims to characterize an economically viable and energy-efficient radiant floor configuration that maintains thermal comfort standards. It incorporates metal sheeting ("Radiant Floor System, Nucap Industries Inc.” 2018.) with small strong spikes (0.76 mm to $2.41 \mathrm{~mm}$ long), that can both decrease construction costs through mechanical adhesion, and increase conductivity through the floor. The physical model of this proposed design is discussed in the following section.

\section{Physical Model}

A schematic two-dimensional representation of the proposed radiant panel is depicted in Figure 3. The heat source can be an electrical heating element or hot/cold water through a network of pipes. It is important to note that the proposed radiant panel is easy to retrofit as it is relatively thin and the top layer utilizes hardwood that is approximately $2.5 \mathrm{~cm}$ thick. This top layer is structurally sufficient to take the impact from building occupants. The bottom most layer of the proposed radiant configuration is subfloor plywood which acts as insulation for minimizing the heat transmitted into the ground. 


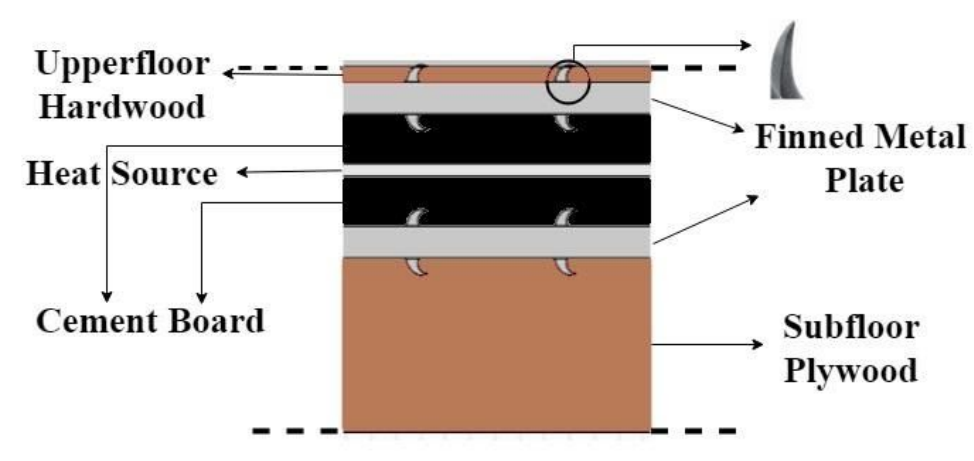

Figure 3. Layer-by-layer construction of the novel radiant panel proposed in the study

A three-dimensional representation of the panel layout and spike variations for the metal plate is presented in Figure 4.

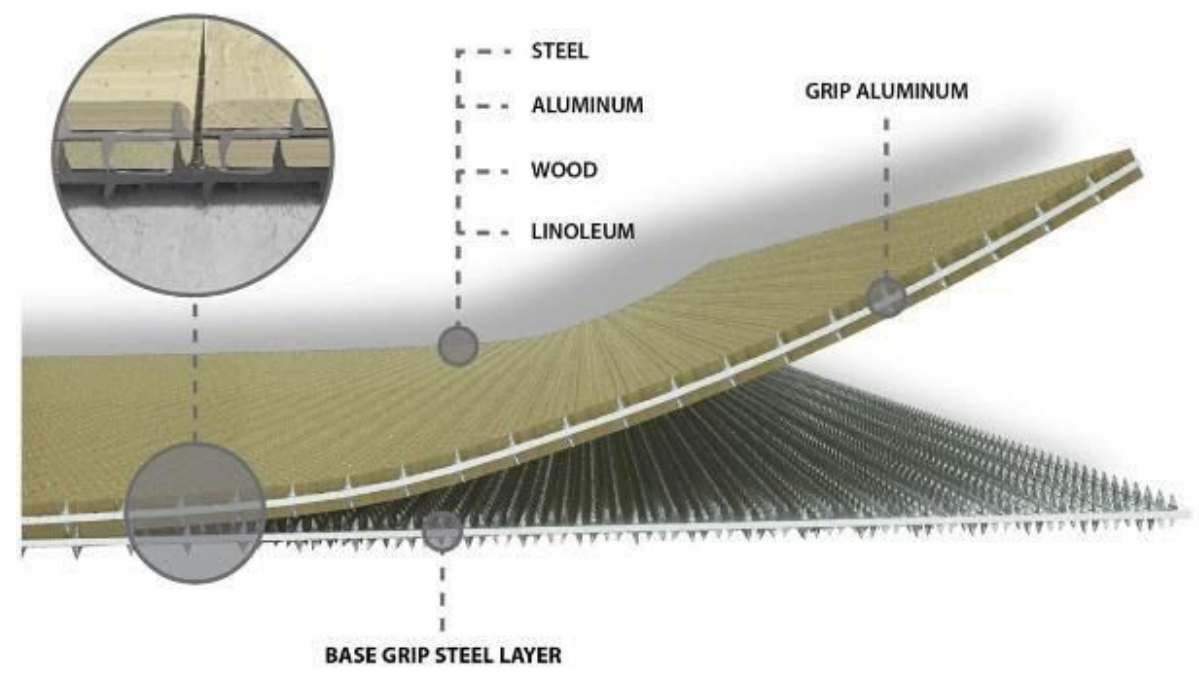

(a) 


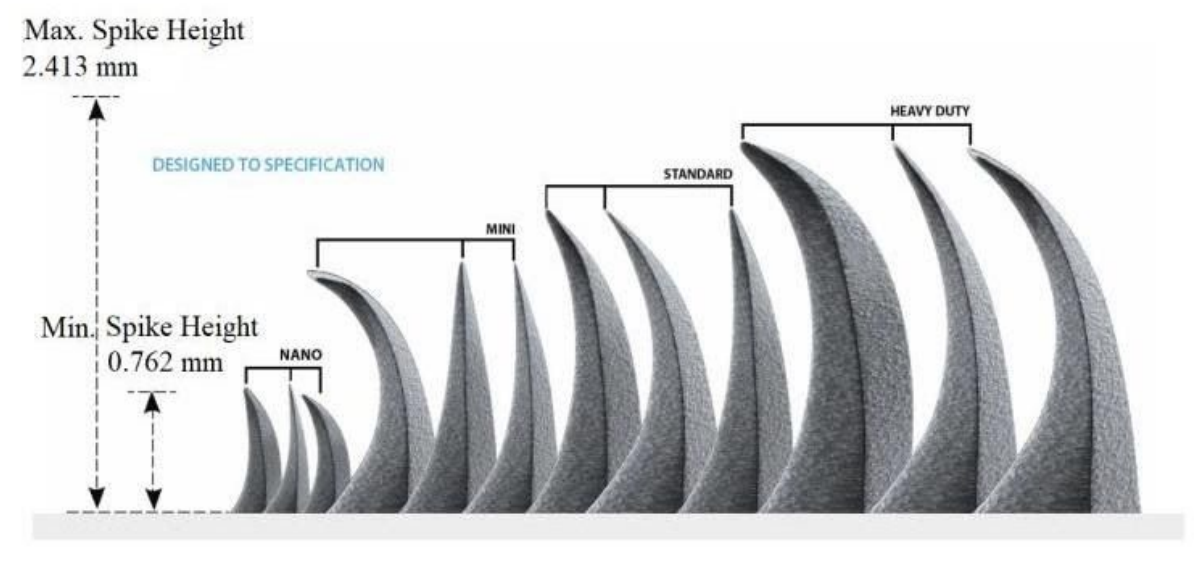

(b)

Figure 4. (a) Three-dimensional panel layout; (b) Spike variations for metal plate ("Radiant Floor System, Nucap Industries Inc." 2018)

For the metal plate with spikes, two material alloys were considered: aluminum alloy $5052 \mathrm{H} 38$ and carbon steel 1010 full hardness (H85-95).

Thermophysical properties of each layer in the panel layout presented in Figure 4 are shown in Table 1. Here, the panel layout and the materials used were the same for the radiant floor heating and the radiant floor cooling applications. 
Table 1. Thermophysical properties of each layer in a radiant panel

\begin{tabular}{|c|c|c|c|c|}
\hline Layer & Material & $\begin{array}{l}\text { Density } \\
\left(\mathbf{k g} / \mathbf{m}^{3}\right)\end{array}$ & $\begin{array}{c}\text { Thermal } \\
\text { Conductivity } \\
\text { (W/m.K) }\end{array}$ & $\begin{array}{c}\text { Heat } \\
\text { Capacity } \\
(\mathrm{J} / \mathrm{kg} . \mathrm{K})\end{array}$ \\
\hline \multirow{2}{*}{$\begin{array}{l}\text { Extended } \\
\text { Surface }\end{array}$} & $\begin{array}{c}\text { Aluminum } \\
5052 \mathrm{H} 38\end{array}$ & 2680 & 138 & 880 \\
\hline & $\begin{array}{c}\text { Carbon } \\
\text { Steel } 1010\end{array}$ & 7870 & 49.8 & 450 \\
\hline $\begin{array}{l}\text { Upper } \\
\text { Floor }\end{array}$ & Hardwood & 720 & 0.16 & 1255 \\
\hline Subfloor & Plywood & 540 & 0.1154 & 1210 \\
\hline $\begin{array}{c}\text { Concrete } \\
\text { Board }\end{array}$ & Cement & 1920 & 0.58 & 1006 \\
\hline
\end{tabular}

\section{Methodology}

The investigation of the enhanced heat transfer surface began by creating a finite element heat transfer model in COMSOL (COMSOL 2016). The purpose of the COMSOL simulation work was to identify the optimal configuration, so the type of heating or cooling method would have no impact on the results as long as it is kept consistent across all scenarios for which the simulation is being iterated. For the heating scenario, a small electric wire heating element was added in the model and the configuration was iterated for different size, shape, and material of the metal plate with spikes. For the cooling scenario, water based cooling was used and was kept consistent across all iterations for different configurations of the proposed radiant panel. Detailed 
conductive heat transfer within the enhanced floor panel, along with convective and radiative heat transfer between the panel and a conditioned interior space, were characterized numerically. The model was used systematically to parametrically quantify surface configurations (varying spike spacing and length), as there were multiple versions available for integration. Newly proposed design modifications were then assessed by performing simulations and comparing the predicted power consumption needed to maintain room temperature. The radiant floor heating system was simulated for an office building environment. The radiant floor cooling system was simulated for an indoor gymnasium-based basketball court.

Upon identifying the optimal configuration based on the efficacy of heat transfer through COMSOL simulations, the geometry of the panel layout was loaded to an energy simulation program called TRNSYS (TRNSYS 2013). Two TRNSYS models were created: one consisting of the proposed novel radiant panel operating in conjunction with a natural gas furnace and central air conditioning $(\mathrm{AC})$ unit and the other consisting of traditional radiant floor system, comprising water pipes embedded in concrete, working in conjunction with the furnace and central AC. Energy saving potential was demonstrated through comparison of both radiant systems using TRNSYS software to perform annual energy simulation and compare the energy consumption of these two distinct systems. In order to assess two radiant configurations (concrete-based conventional and novel) under different climatic conditions, three scenarios were studied: heating dominant, a climate that leads to total heating demand over the course of the year being greater than the total cooling demand by more than 3 orders in magnitude; cooling dominant, total cooling demand is greater than the heating demand by more than 3 orders in magnitude; and neutral zone, total heating and cooling demand 
are on the same order. The detailed description of the COMSOL and TRNSYS models is presented in subsequent sections, respectively.

\subsection{Simulation for the Identification of Optimal Configuration}

\subsubsection{Computational Domain}

For the heat transfer simulation, two orthogonal cross sections have been considered; parallel to the heat source and perpendicular to the heat source. The lengths of the spikes are $2.29 \mathrm{~mm}(0.09 \mathrm{in})$ and $1.52 \mathrm{~mm}(0.06 \mathrm{in})$ based on ease of manufacturability. The dimensions of the various layers are given in Figure 5. Here, the heat source is a hot/cold water pipe.

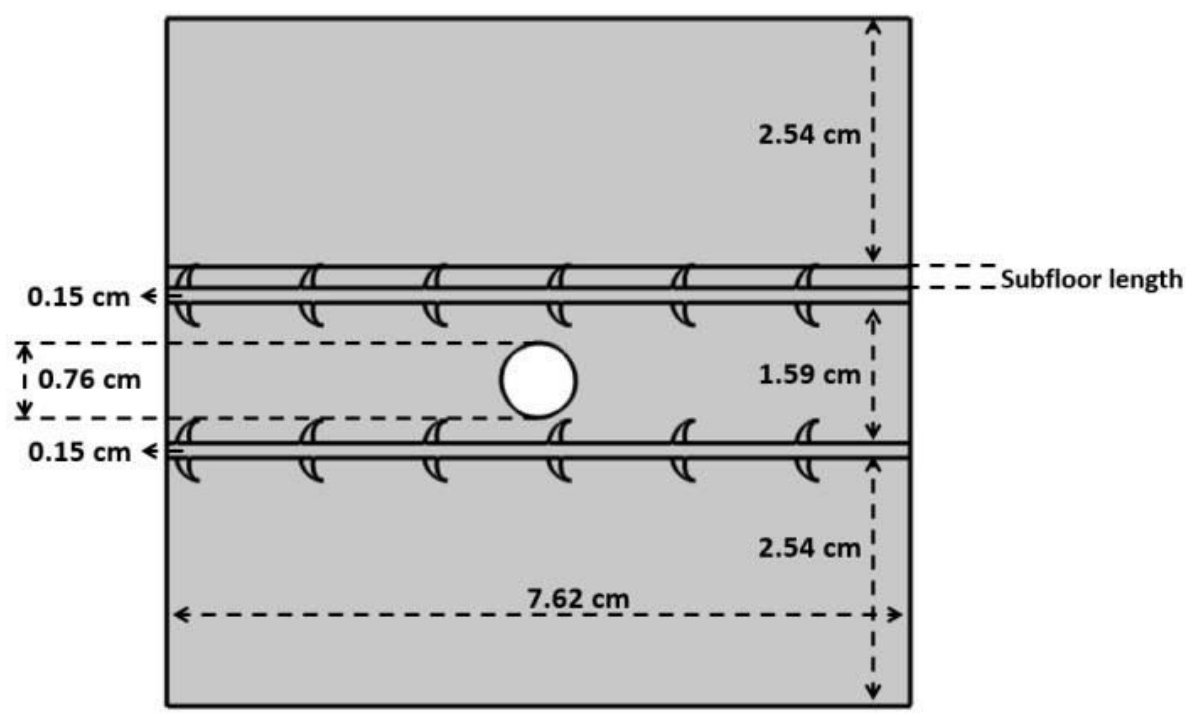

Figure 5. Dimensions of the radiant panel (perpendicular to the heat source)

\subsubsection{Mesh Independence}

The mesh independence analysis is carried out to find the optimum number of nodes for the simulation. Using the in-built mesh settings, the optimum number of nodes was determined to be 27,409 for radiant floor heating and radiant floor cooling — striking a good balance between computational power and preciseness. All the simulation results 
presented in subsequent sections utilize at least 27,409 nodes with a triangular mesh.

\subsubsection{Boundary Conditions}

For the radiant floor heating application, the initial temperature of the entire panel and air layer, the topmost layer of thickness $2.54 \mathrm{~cm}$ on Figure 5, were assumed to be $10^{\circ} \mathrm{C}$. The left and right side of the panel layout had a periodic condition applied to them and thus both sides of the wall were maintained at the same temperatures. In accordance with ASHRAE Standard 55-1992, 30\% relative humidity was considered representing typical indoor environment conditions for a winter season (“ANSI/ASHRAE Standard 55-1992, Thermal Environmental Conditions for Human Occupancy,” 1992). The top part of the domain was subjected to thermal insulation boundary conditions, as would be the case with the building materials providing insulation to the room. The bottom part was subjected to the constant temperature boundary condition.

For the radiant floor cooling application, in accordance with ASHRAE standard $55-1992,50 \%$ relative humidity was considered representing typical indoor environment conditions for the summer season ("ANSI/ASHRAE Standard 55-1992, Thermal Environmental Conditions for Human Occupancy," 1992). An initial condition of $28^{\circ} \mathrm{C}$ was used representing a typical indoor temperature on a sunny day in the summer. Also, a periodic condition was used for both sides of the model.

Also, the convective heat transfer coefficient for the air was taken to be between 22-34 W/m ${ }^{2} \mathrm{~K}$, varying with temperature in the range of $10-22^{\circ} \mathrm{C}$ (COMSOL 2016). Using the psychrometric chart, relative humidity was used to calculate dew point temperature for both heating and cooling scenarios to check for potential condensation at the floor surface. 


\subsubsection{Solution Procedure}

For the radiant floor heating scenario, different nuances of the panel layouts: different spike variations (spacing, length and fitting with the upper layer) and material for the metal plate, were first modelled. Through a careful review of these simulation results, an optimal configuration was determined and then the effect of having more than two metal plates with spikes was studied.

For the radiant floor cooling application, two different simulations were run. Similar to the radiant floor heating application, the first of the simulations was run to quantify efficacy of the enhanced metal plate with spikes and to understand how spike spacing, and material properties would influence heat distribution. Once optimal panel dimensions and metal plate material were determined, a radiant floor cooling application in an indoor gymnasium-based basketball court was simulated. Since electric resistance cannot be used for cooling, water was used as a heat carrier medium. The temperature and flow rate of the water for iterative simulation work was $18^{\circ} \mathrm{C}$ at 0.8 gallons per minute (equal to $0.05 \mathrm{~L} / \mathrm{s}$ ), respectively. For the radiant floor cooling application in the basketball court, it was important to understand three heat transfer mechanisms of cooling: conduction through the floor, evaporative cooling of sweat from the basketball player, and radiation due to the temperature difference between the floor and the player's body. Using Fanger's scale and considering an active metabolism of a basketball player, a body temperature of $38^{\circ} \mathrm{C}$ was used ("ANSI/ASHRAE Standard 55-1992, Thermal Environmental Conditions for Human Occupancy,” 1992). A typical indoor basketball court height of $5.2 \mathrm{~m}(17 \mathrm{ft})$ was used, along with a basketball player height of $1.8 \mathrm{~m}(6 \mathrm{ft})$ similar to a study conducted by Zhao et al. (2013). The model including the human body is shown in Figure 6. In the present work, 
the model was simplified to a sphere at $38^{\circ} \mathrm{C}$ and $400 \mathrm{~W} / \mathrm{m}^{2}$ of metabolic rate (Olesen 1997).

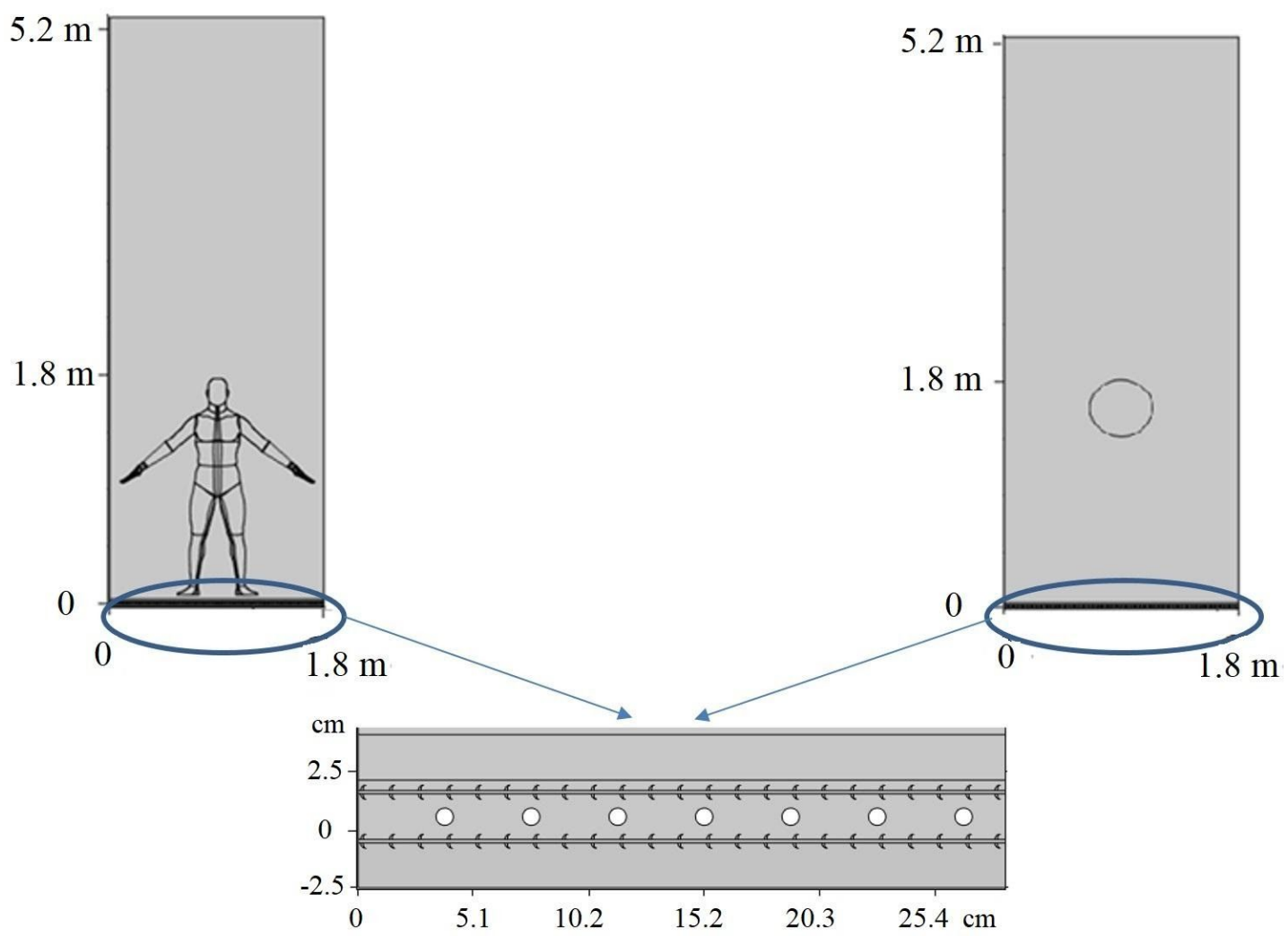

Figure 6. Basketball court radiant floor cooling application: left to right shows the transition to the simplified model and the bottom image shows a detailed view of array of an array of cold water pipes embedded in a radiant panel configuration

\subsection{Comparison of Optimal Configuration with Traditional Radiant System}

\subsubsection{Building Envelope Details}

For the transient energy simulation, a single thermal zone of approximately $46 \mathrm{~m}^{2}$ or $500 \mathrm{ft}^{2}$ area (a typical studio apartment unit's square footage) comprising a typical construction envelope (walls, ceiling, flooring etc.) was constructed. The floor-to-ceiling height was $3 \mathrm{~m}$ and a room of $6 \mathrm{~m}$ width by $8 \mathrm{~m}$ length was built in the software. The envelope was subjected to three different climatic conditions, as discussed in the methodology section: heating dominant, cooling dominant, and neutral. 
Using 30-year average weather data stored in the TRNSYS library, heating dominant and cooling dominant climates were simulated for two different locations: Toronto, Canada and Phoenix, USA, respectively.

The concrete-based radiant system was modelled using the layer-by-layer construction of a study conducted by Zhang, Liu, and Jiang (2012). Schematics of this configuration are presented in Figure 7. The thermal performance of concrete-based radiant system was compared with novel radiant panel configuration presented in Figure 5.

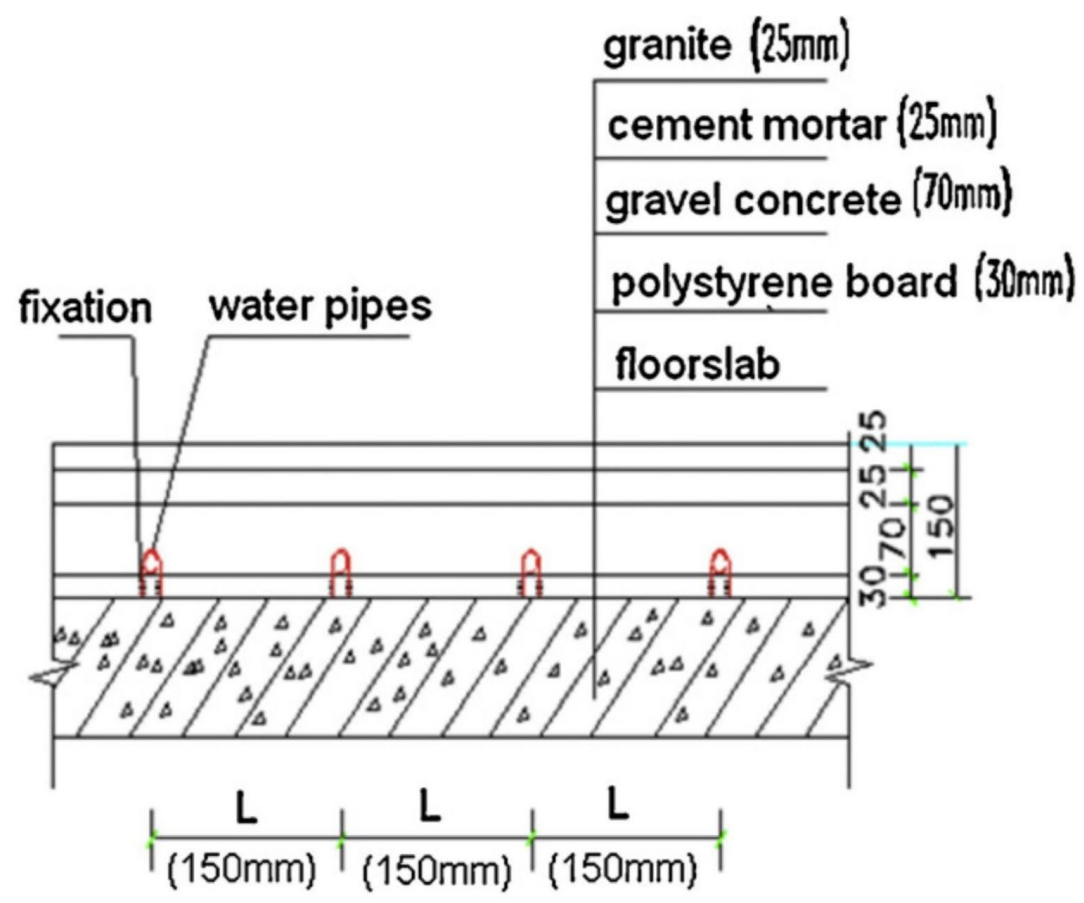

Figure 7. Schematics of the concrete-based system; reproduced from (Zhang, Liu, and Jiang 2012)

\subsubsection{System Parameters}

Space heating and space cooling was provided by hybridizing radiant floor systems, conventional and novel, with a natural gas furnace and air conditioning (AC) unit. The natural gas furnace was assumed to work with a constant efficiency of $85 \%$. For space cooling, a 1-ton AC unit with a seasonal energy efficiency ratio (SEER) of 17 was 
added. Constant utility costs of $\$ 0.30$ per $\mathrm{m}^{3}$ of natural gas burnt and $\$ 0.12$ per $\mathrm{kWh}$ were used to simplify the calculation of operational cost savings. Constant GHG emission factors were considered in this study; for natural gas and electricity consumption, these were $1.86 \mathrm{~kg}$ per $\mathrm{m}^{3}$ of natural gas burnt and $0.04 \mathrm{~kg}$ per $\mathrm{kWh}$ of electricity used, respectively.

For traditional and novel radiant systems, the water inlet temperature of $18^{\circ} \mathrm{C}$ and $30^{\circ} \mathrm{C}$ was used for the cooling scenario and heating scenario, respectively. The water supply flow rate of $0.80 \mathrm{gpm}(0.05 \mathrm{~L} / \mathrm{s})$ was used for cooling and hot water with $1.10 \mathrm{gpm}(0.07 \mathrm{~L} / \mathrm{s})$ flow rate circulated for the heating scenario. Consistent with industry practices for radiant systems, the pipe diameter of $0.76 \mathrm{~cm}$ was used. The cooling and heating of the supply water for the radiant system was achieved using an air-to-water heat pump (AWHP) with a constant coefficient of performance (COP) of

3.0. While base heating and cooling were provided by the radiant floor system powered by AWHP, supplementary heating and cooling were provided by the natural gas furnace and central $\mathrm{AC}$ unit, respectively. The air setpoint temperatures of $20^{\circ} \mathrm{C}$ and $26^{\circ} \mathrm{C}$ were used for heating and cooling scenario, respectively. Simulations evaluating operative temperature were run to ensure their values were within the acceptable range established by the ASHRAE standards.

\subsubsection{TRNSYS System Layout}

As demonstrated in Figure 8, weather data (dry-bulb air temperature, relative humidity, mean wind speed etc.) is passed on to the building envelope as an input to evaluate heating and cooling load. The building envelope, denoted as Type 56, comprises radiant floor configurations as active layers consisting of heat sources. Infiltration values are manually transmitted to the building envelope module. The operating temperature was simulated in TRNSYS to ensure compliance with the aforementioned ASHRAE 
standard. Simulations were run for three different climatic conditions for the aforementioned locations for 8760 hours of the year.

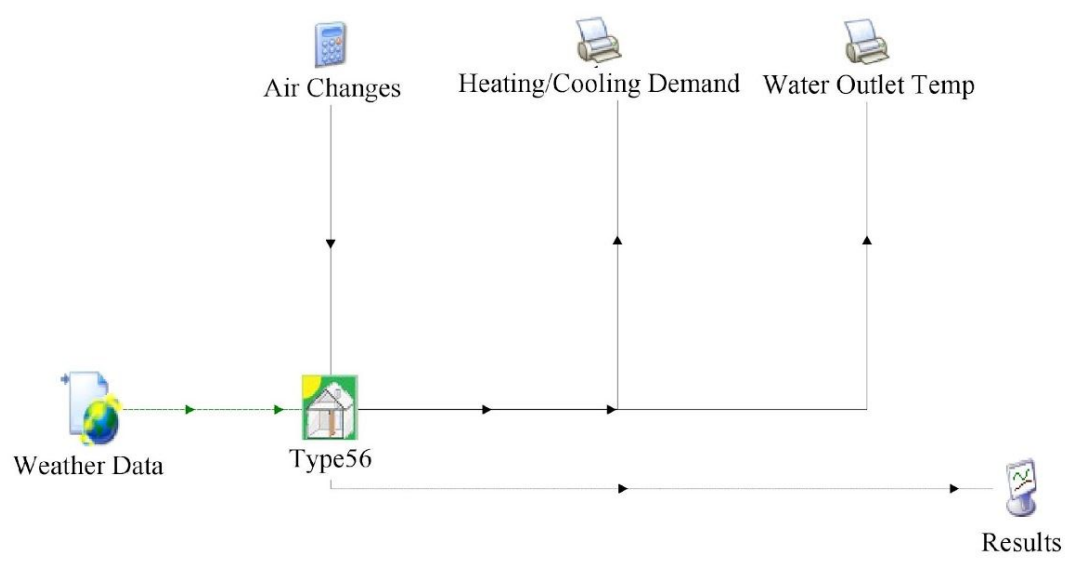

Figure 8. Schematics of the TRNSYS model

Three different TRNSYS models with the layout of Figure 8 were created for different climatic conditions. For each model, the radiant system parameters were put into the 'Type 56' component module which contains the building envelope details. Then, the data containing heating and cooling demand that will be supplied by the conventional heating and cooling system was exported in a spreadsheet. For each TRNSYS model, two different simulations were run; a concrete-based radiant system and the novel radiant panel with spikes.

Since three-dimensional grids for the application of finite difference or finite element method needs to be intractably dense in order to get results with a high degree of precision, TRNSYS employs an alternative method. The analytical framework for the stationary solution of a thermo-active element and the development of thermal resistance network is discussed in-depth in TRNSYS documentation (Wisconsin-Madison 2010). 


\section{$4 \quad$ Results and Discussion}

\subsection{Simulation for the Identification of Optimal Configuration}

\subsubsection{Radiant Floor Heating}

Initial simulations were performed to observe the impact of spike protrusion, the material of the metal plate with spikes, and spike length. The results obtained for each of these variations are summarized in Table 2. Table 2 shows the amount of time it takes to heat the air layer from $10^{\circ} \mathrm{C}$, the initial condition, to $22^{\circ} \mathrm{C}$, the setpoint temperature for four scenarios; a metal plate that is not enhanced with small spikes, a spike barely touching the upper floor plywood, a spike nailed down to the upper floor plywood, and a spike under the plywood. For each simulation in COMSOL, the time taken to reach the setpoint temperature while running $10 \mathrm{~W}$ of heating element power was determined and the energy consumed over the time was calculated.

Energy reduction shown in Table 2 was calculated using equation (1). $E_{f}$ and $E_{n f}$ denote energy consumption for the metal plate with a discrete orientation of spikes and the metal plate without spikes - just a flat metal plate configuration, respectively.

$$
\text { Energy Reduced }(\%)=\frac{E_{f}-E_{n f}}{E_{n f}} \times 100 \#(1)
$$

Table 2. Results for the metal plate with different spikes orientations (heating from $10^{\circ} \mathrm{C}$ to setpoint temperature of $22^{\circ} \mathrm{C}$ ) 


\begin{tabular}{|c|c|c|c|c|}
\hline Scenario & $\begin{array}{c}\text { Plate } \\
\text { Material }\end{array}$ & $\begin{array}{c}\text { Spike } \\
\text { Length } \\
\text { mm (in) }\end{array}$ & $\begin{array}{c}\text { Setpoint } \\
\text { Time } \\
\text { (min) }\end{array}$ & $\begin{array}{c}\text { Energy } \\
\text { Reduction } \\
(\%)\end{array}$ \\
\hline \multirow[t]{5}{*}{ Without spikes } & \multicolumn{2}{|l|}{-} & 68 & \multirow[b]{2}{*}{50} \\
\hline & $\mathrm{Al}$ & $\begin{array}{c}1.52 \\
(0.06) \\
\end{array}$ & 34 & \\
\hline & $\mathrm{C}$ & $\begin{array}{c}1.52 \\
(0.06)\end{array}$ & 39 & 43 \\
\hline & $\mathrm{Al}$ & $\begin{array}{c}2.29 \\
(0.09)\end{array}$ & 30 & 56 \\
\hline & $\mathrm{C}$ & $\begin{array}{c}2.29 \\
(0.09)\end{array}$ & 36 & 47 \\
\hline & $\mathrm{Al}$ & $\begin{array}{c}1.52 \\
(0.06)\end{array}$ & 28 & 59 \\
\hline & $\mathrm{C}$ & $\begin{array}{c}1.52 \\
(0.06)\end{array}$ & 33 & 51 \\
\hline & Al & $\begin{array}{c}2.29 \\
(0.09)\end{array}$ & 25 & 63 \\
\hline & $\mathrm{C}$ & $\begin{array}{c}2.29 \\
(0.09)\end{array}$ & 31 & 54 \\
\hline & $\mathrm{Al}$ & $\begin{array}{c}1.52 \\
(0.06)\end{array}$ & 46 & 32 \\
\hline & $\mathrm{C}$ & $\begin{array}{c}1.52 \\
(0.06)\end{array}$ & 52 & 23 \\
\hline
\end{tabular}

It can be seen from Table 2 that an aluminum metal plate with spikes with 2.29 $\mathrm{mm}(0.09$ in) spike length is the optimal configuration based on the energy reduction and the amount of time needed to reach setpoint temperature.

For the optimal configuration, the temperature distributions across the air layer were simulated. Using an electrical heating element as the heat source, temperature distributions, parallel and perpendicular to the heat source, after the air layer has reached the setpoint temperature, were plotted as shown in Figure 9. Since the system is subjected to constant room temperature conditions at the bottom, the temperature is 
much lower at the bottom than the rest of the domain in Figure 9. The temperature gradient around the heat source is presented through the use of isothermal contours in Figure 10 . These results were plotted for a heat source emitting $108 \mathrm{~W} / \mathrm{m}^{2}$, which is the minimum amount of power used for radiant floor heating in the industry (Izquierdo and de Agustín-Camacho 2015; Zhou and He 2015; D. Zhang, Cai, and Wang 2013).

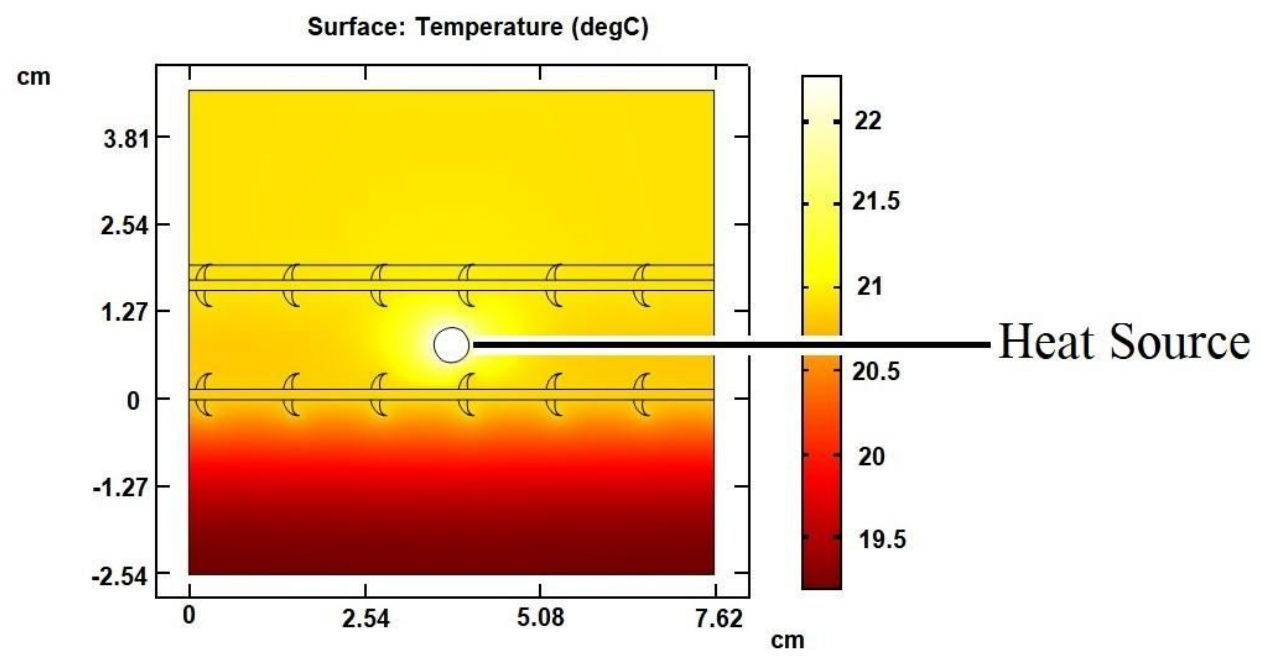

(a)

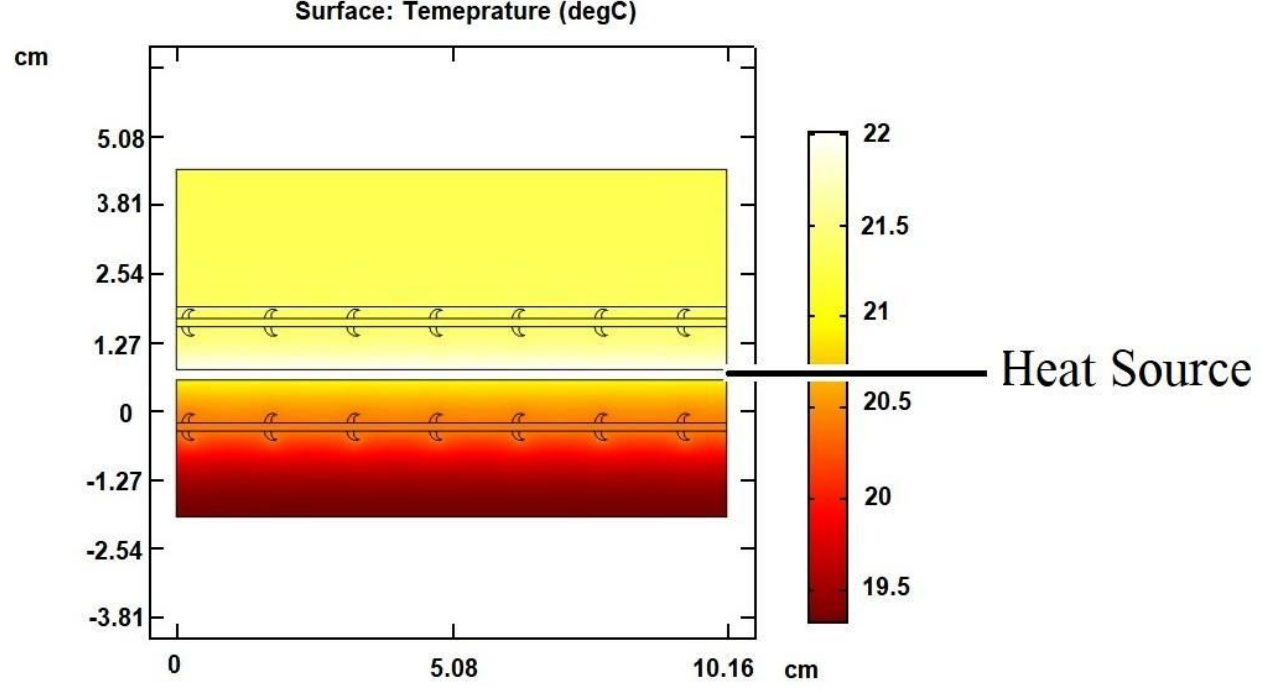

(b)

Figure 9. Temperature distribution plots: (a) perpendicular to the heat source; and (b) parallel to the heat source 


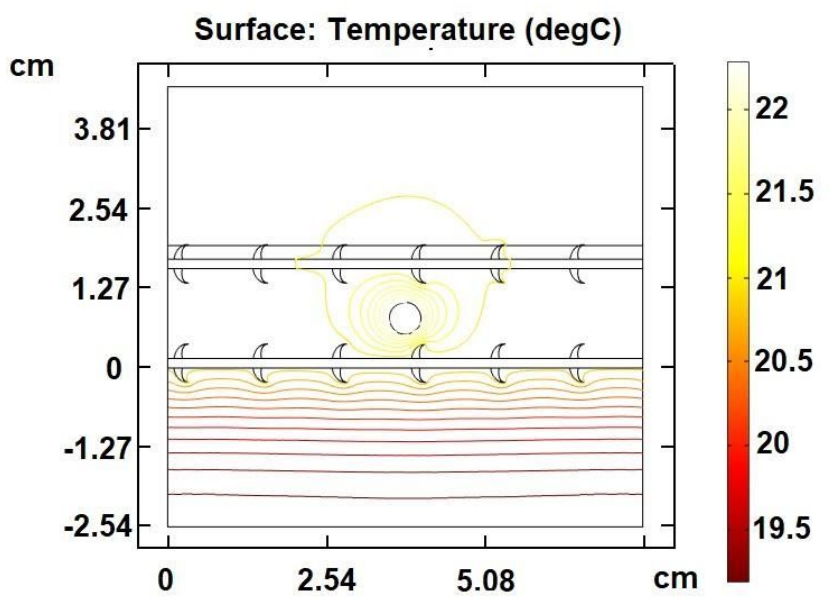

Figure 10. Temperature gradient around the heat source presented through isothermal contour lines

It is important to note that the spikes can be oriented parallel or perpendicular to the heat source depending on the manufacturing process. In the preliminary analysis performed here, the same spike profile was used in both configurations as presented in Figure 9 for ease of their recognition and simulation.

As can be seen from Figure 9 (a) and (b), slices parallel and perpendicular to the heat source both yield uniform horizontal temperature distributions. As presented in Table 2, the optimal configuration reaches the $22^{\circ} \mathrm{C}$ setpoint temperature in under 25 minutes, as compared to the without-spikes configuration which takes 68 minutes to reach the setpoint temperature.

In addition, the effect of having an extra metal plate with spike layers was observed. Consistent with expectations, the addition of extra layers resulted in extra time needed to reach the setpoint temperature. This can be explained from the fact that having an extra metal plate with spikes sandwiched in between concrete boards adds thermal mass to the system. This effect is illustrated in the temperature distribution plots presented in Figure 11. 


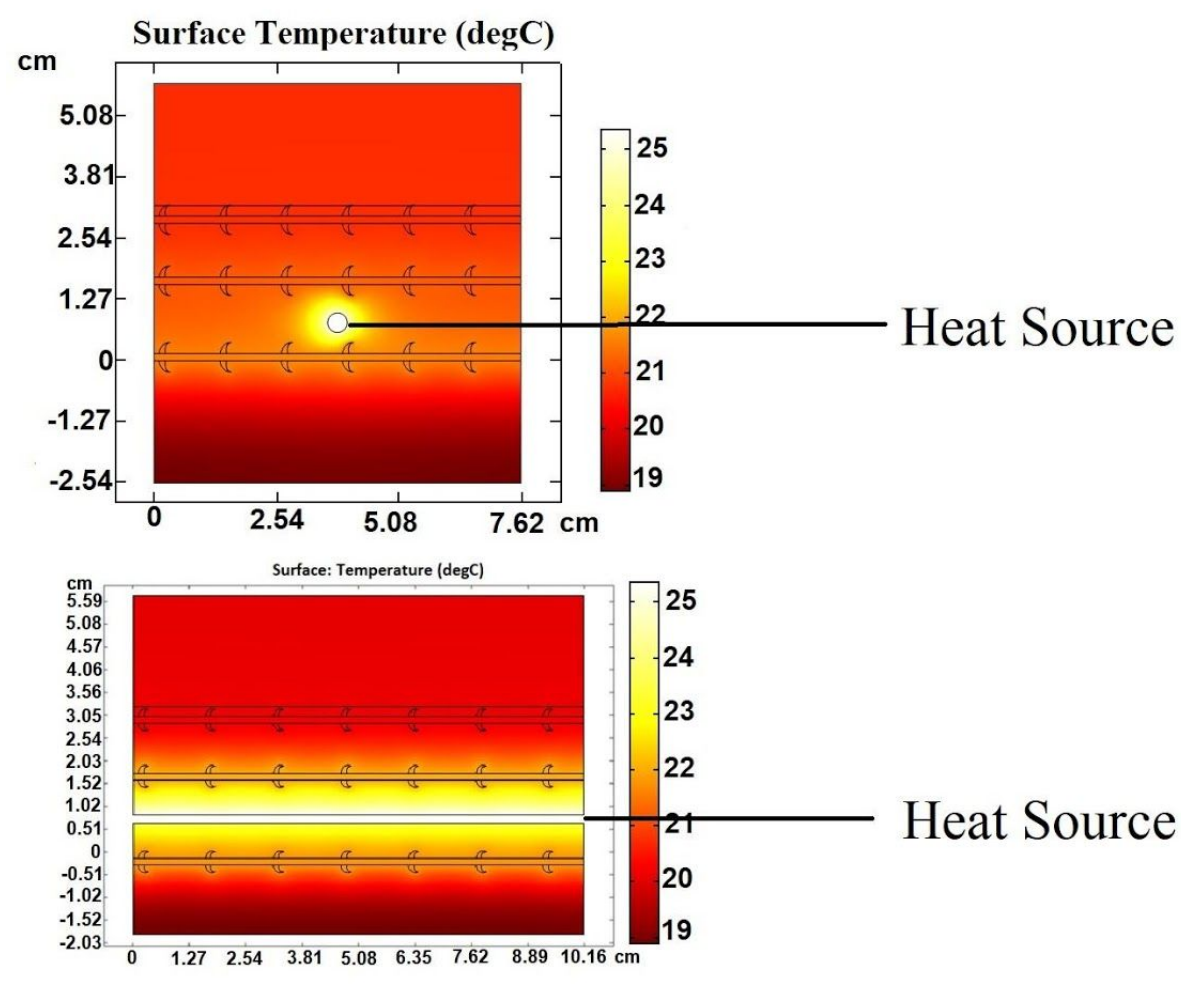

Figure 11. Temperature distribution plots with additional metal plate: (a) perpendicular to the heat source; and (b) parallel to the heat source

It is important to note that for the floor heating application, a small electric heating element was used. Since this part of the study was preliminary in the early stages of the project, it was important to investigate the feasibility with the heating mechanisms that are not computationally complex such as water-based heating. It was important to check whether the radiant floor system yielded uncomfortably hot surface temperature or not. The surface temperatures for all configurations were in the comfortable range of $19^{\circ} \mathrm{C}$ to $29^{\circ} \mathrm{C}$ which is recommended by the standards discussed earlier.

\subsubsection{Radiant Floor Cooling}

For the radiant floor cooling application in the basketball court, only the spike-under-the-surface scenario was considered. This is in line with construction 
methods of floors of basketball courts (Zhao, Liu, and Jiang 2016). Hence, the optimal configuration had to be iteratively simulated only for different materials for the metal plate with spikes. Consistent with a radiant floor heating layout, only two material candidates were considered: aluminum alloy and carbon steel. Since water with the temperature value ranging from $15^{\circ} \mathrm{C}$ to $18^{\circ} \mathrm{C}$ is to be used to cool the floor, an air-to-water heat pump was assumed to be used to supply water to the pipes. Table 3 shows the amount of time it takes to cool the air layer from the $30^{\circ} \mathrm{C}$ initial condition, to the $24^{\circ} \mathrm{C}$ cooling setpoint temperature for a heat pump with the COP value of 3.0 , operating under various cooling rates. Similar to prior results for the radiant floor heating layout, it was determined that using an aluminum plate with small spikes resulted in the most efficient configuration.

Table 3. Results for the metal plate with different materials working with the heat pump

\begin{tabular}{|c|c|c|c|}
\hline $\begin{array}{c}\text { Cooling Rate } \\
\left(\mathbf{W} / \mathbf{m}^{2}\right)\end{array}$ & $\begin{array}{c}\text { Power } \\
\text { Consumption of } \\
\text { Heat Pump (W) }\end{array}$ & $\begin{array}{c}\text { Cooldown } \\
\text { Time- } \\
\text { Aluminum } \\
\text { Alloy Plate } \\
\text { (min) }\end{array}$ & $\begin{array}{c}\text { Cooldown } \\
\text { Time- } \\
\text { Carbon Steel } \\
\text { Plate (min) }\end{array}$ \\
\hline 10.9 & 7 & 45 & 53 \\
\hline 16.4 & 10 & 35 & 39 \\
\hline 27.3 & 17 & 26 & 28 \\
\hline 54.7 & 33 & 17 & 19 \\
\hline
\end{tabular}

Also, temperature distributions for the air layer were uniform and floor surface temperatures were not lower than the design dew point temperature of $16^{\circ} \mathrm{C}$ or the acceptable minimum floor surface temperature of $19^{\circ} \mathrm{C}$.

A common problem with radiant cooling systems is condensation. To ensure that the air temperature near the floor surface does not drop below the dew point 
temperature, all modes of heat transfer were considered. Also, air temperature near the floor surface was simulated to make sure it was higher than the dew point temperature.

Next, the optimal radiant panel configuration was simulated for an indoor basketball court environment. To account for evaporative cooling of human body, a moist air transport module was added and $0.4 \mathrm{~m}^{3} / \mathrm{min}$ (15 Cubic Feet per Minute (CFM)) per person flow rate was used, in accordance with ASHRAE Standard 62 (1999). An air velocity of $0.1 \mathrm{~m} / \mathrm{s}$ was used. As mentioned in the study (Zhao, Liu, and Jiang 2016), this is the most commonly used value in large space buildings. The initial condition and temperature distribution once the setpoint temperature is reached are shown in Figure 12. It is important to note that the hot spot shown in Figure 12 is the heat source having the metabolic rate of the simplified human body presented in spherical shape. Also, temperature asymmetry was observed due to the convective effects near the outlet of the ventilation flow in the top right of the image (shown through the arrow in Figure 12).
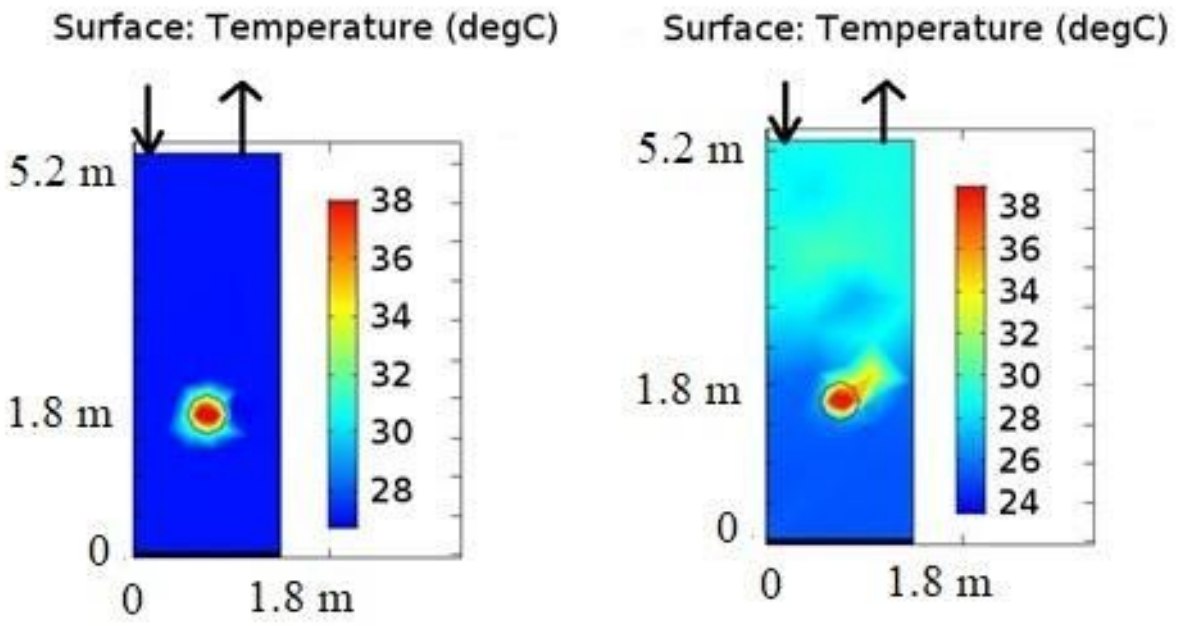

Figure 12. Radiant floor cooling for basketball court application. The image on the left represents the initial condition of a sphere starting at $38^{\circ} \mathrm{C}$. The image on the right is a screen capture once the setpoint temperature of $24^{\circ} \mathrm{C}$ has been reached. 
In Figure 12, the image on the left and right have different bottom temperature (blue denotes the lowest temperature in the respective image); the bottom part of the right side of Figure 12 is at $24^{\circ} \mathrm{C}$ whereas the left side denoting the initial condition is $28^{\circ} \mathrm{C}$. The temperature in the bottom part has decreased from the initial condition to the time it takes to reach the setpoint temperature.

\subsection{Comparison of Optimal Configuration with Traditional Radiant System}

Ambient temperature for the TRNSYS model simulation is presented in Figure 13 for all three climates simulated in this study: heating dominant, Toronto, Canada; cooling dominant, Phoenix, USA; and neutral zone, Los Angeles, USA.

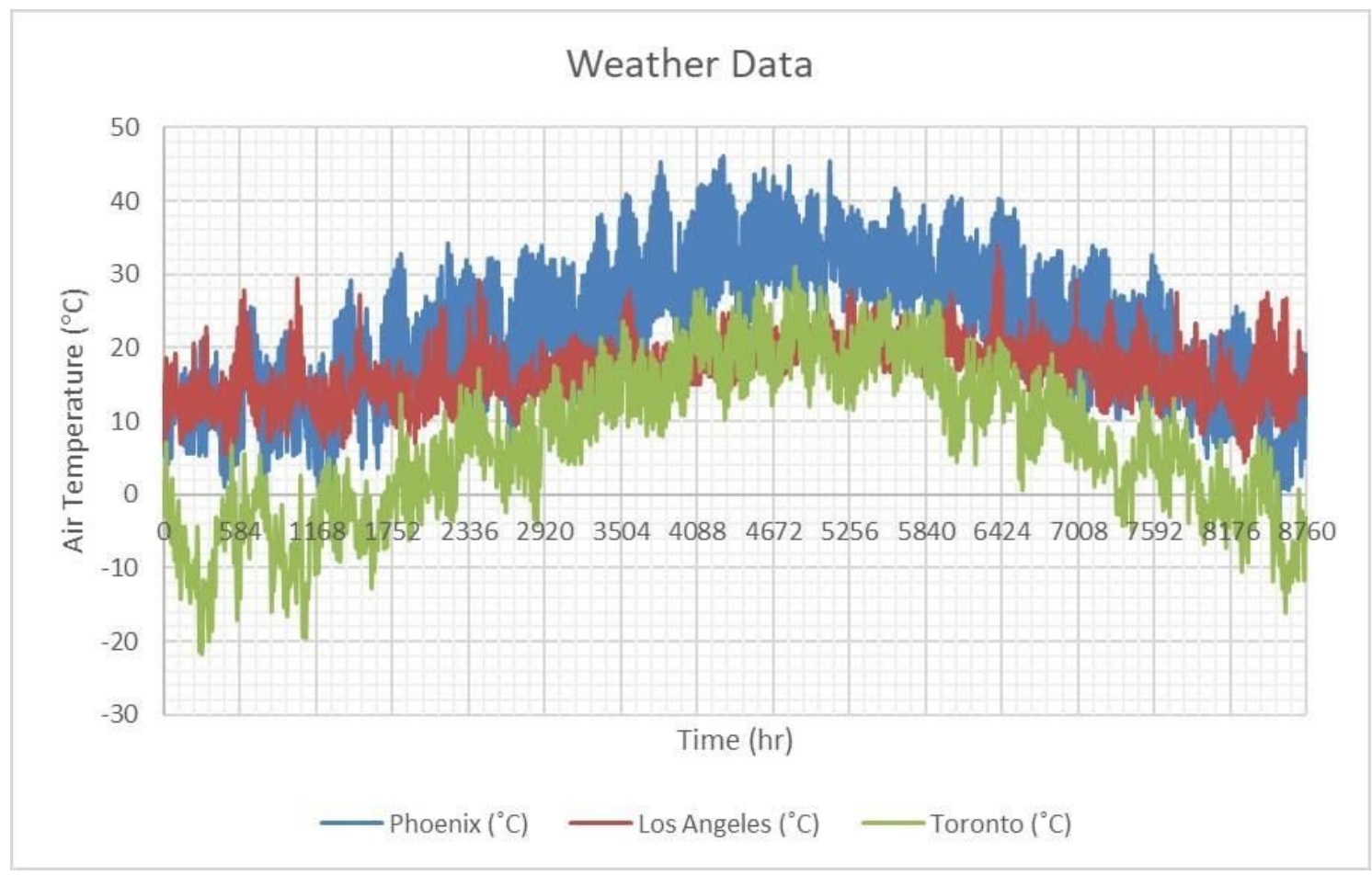

Figure 13. Plot of the outdoor air temperature for three different climates analyzed in the study

The comparison between the novel panel proposed in the study and concrete-based radiant configuration year-long simulated operation for the building envelope subjected to Toronto, Canada's climatic conditions was performed and the 
results were summarized in Table 4 . Here, a commonly used energy conversion factor was applied to convert natural gas from $\mathrm{m}^{3}$ to $\mathrm{kWh}$. Using the efficiency of each component and utility rates, the energy consumption of the natural gas furnace, central AC, and AWHP was calculated. The novel panel yielded 36\% less energy consumption, $25 \%$ lower operating costs, and $44 \%$ lower GHG emissions compared to the operation of concrete-based radiant system.

Table 4. Annual performance comparison between novel and concrete-based panel for heating dominant building subjected to Toronto, Canada climatic conditions

\begin{tabular}{|c|c|c|c|c|}
\hline & $\begin{array}{l}\text { Natural } \\
\text { Gas } \\
\text { Furnace }\end{array}$ & $\begin{array}{c}\text { Central } \\
\text { AC }\end{array}$ & AWHP & Total \\
\hline $\begin{array}{c}\text { Energy } \\
\text { Consumed } \\
\text { Novel Panel }\end{array}$ & $\begin{array}{c}2860 \mathrm{kWh} \\
\left(271 \mathrm{~m}^{3}\right)\end{array}$ & $0 \mathrm{kWh}$ & $3054 \mathrm{kWh}$ & $5914 \mathrm{kWh}$ \\
\hline $\begin{array}{c}\text { Energy } \\
\text { Consumed } \\
\text { Concrete-based }\end{array}$ & $\begin{array}{c}5500 \mathrm{kWh} \\
\left(522 \mathrm{~m}^{3}\right)\end{array}$ & $15 \mathrm{kWh}$ & $3729 \mathrm{kWh}$ & $9244 \mathrm{kWh}$ \\
\hline $\begin{array}{c}\text { Operating Costs } \\
\text { Novel Panel }\end{array}$ & $\frac{\$ 1.70}{m^{2} \cdot y r}$ & $\frac{\$ 0}{m^{2} \cdot y r}$ & $\frac{\$ 7.10}{m^{2} \cdot y r}$ & $\frac{\$ 8.79}{m^{2} \cdot y r}$ \\
\hline $\begin{array}{l}\text { Operating Costs } \\
\text { Concrete-based }\end{array}$ & $\frac{\$ 3.26}{m^{2} \cdot y r}$ & $\frac{\$ 0.04}{m^{2} \cdot y r}$ & $\frac{\$ 8.67}{m^{2} \cdot y r}$ & $\frac{\$ 11.9}{m^{2} \cdot y r}$ \\
\hline $\begin{array}{c}\text { GHG Emission } \\
\text { Novel Panel }\end{array}$ & $504 \mathrm{~kg}$ & $0 \mathrm{~kg}$ & $122 \mathrm{~kg}$ & $626 \mathrm{~kg}$ \\
\hline $\begin{array}{l}\text { GHG Emission } \\
\text { Concrete-based }\end{array}$ & $969 \mathrm{~kg}$ & $1 \mathrm{~kg}$ & $149 \mathrm{~kg}$ & $1119 \mathrm{~kg}$ \\
\hline
\end{tabular}

Similarly, for the cooling dominant scenario, simulated for climatic conditions of Phoenix, USA, the operation of the novel radiant panel was $50 \%$ cheaper and $55 \%$ less GHG emissive all while reducing the total energy consumption by $42 \%$ compared to the concrete-based radiant system operation. The results are summarized in Table 5. 
Table 5. Annual performance comparison between novel and concrete-based panel for cooling dominant building subjected to Phoenix, USA climatic conditions

\begin{tabular}{|c|c|c|c|c|}
\hline $\begin{array}{c}\text { Energy } \\
\text { Consumed } \\
\text { Novel Panel }\end{array}$ & $\begin{array}{c}\text { Natural } \\
\text { Gas } \\
\text { Furnace }\end{array}$ & $\begin{array}{c}\text { Central } \\
\text { AC }\end{array}$ & AWHP & Total \\
\hline $\begin{array}{c}\text { Energy } \\
\text { Consumed } \\
\text { Concrete-based }\end{array}$ & $\begin{array}{c}571 \mathrm{kWh}^{3} \\
\left(54 \mathrm{~m}^{3}\right)\end{array}$ & $\begin{array}{c}712 \\
\mathrm{kWh}\end{array}$ & $2474 \mathrm{kWh}$ & $3238 \mathrm{kWh}$ \\
\hline $\begin{array}{c}\text { Operating } \\
\text { Costs } \\
\text { Novel Panel }\end{array}$ & $\frac{\$ 0.031}{m^{2} \cdot y r}$ & $\frac{\$ 1.78}{m^{2} \cdot y r}$ & $\frac{\$ 2.33}{m^{2} \cdot y r}$ & $\frac{\$ 4.14}{m^{2} \cdot y r}$ \\
\hline $\begin{array}{c}\text { Operating } \\
\text { Costs } \\
\text { Concrete-based }\end{array}$ & $\frac{\$ 0.34}{m^{2} \cdot y r}$ & $\frac{\$ 4.60}{m^{2} \cdot y r}$ & $\frac{\$ 3.05}{m^{2} \cdot y r}$ & $\frac{\$ 8.00}{m^{2} \cdot y r}$ \\
\hline $\begin{array}{c}\text { GHG Emission } \\
\text { Novel Panel }\end{array}$ & $9 \mathrm{~kg}$ & $28 \mathrm{~kg}$ & $99 \mathrm{~kg}$ & $136 \mathrm{~kg}$ \\
\hline $\begin{array}{c}\text { GHG Emission } \\
\text { Concrete-based }\end{array}$ & $101 \mathrm{~kg}$ & $74 \mathrm{~kg}$ & $130 \mathrm{~kg}$ & $304 \mathrm{~kg}$ \\
\hline
\end{tabular}

For the simulation under neutral climatic conditions of Los Angeles, USA, the air temperature throughout the year was close to the established setpoint temperature inside the zone and thus lower energy consumption was seen overall for all three space heating and space cooling equipment sets. The results for this scenario are presented in Table 6. Overall, with the novel panel scenario, energy consumption reduced by $44 \%$ and the GHG emissions and costs were lower by $58 \%$ and $41 \%$, respectively. 
Table 6. Annual performance comparison between novel and concrete-based panel for neutral building subjected to Los Angeles, USA climatic conditions

\begin{tabular}{|c|c|c|c|c|}
\hline $\begin{array}{c}\text { Energy } \\
\text { Consumed } \\
\text { Novel Panel }\end{array}$ & $\begin{array}{c}\text { Natural } \\
\text { Gurnace } \\
\left(0.3 \mathrm{~m}^{3}\right)\end{array}$ & $\begin{array}{c}\text { Central } \\
\text { AC }\end{array}$ & AWHP & Total \\
\hline $\begin{array}{c}\text { Energy } \\
\text { Consumed } \\
\text { Concrete-based }\end{array}$ & $\begin{array}{c}281 \mathrm{kWh} \\
\left(27 \mathrm{~m}^{3}\right)\end{array}$ & $6 \mathrm{kWh}$ & $2297 \mathrm{kWh}$ & $2584 \mathrm{kWh}$ \\
\hline $\begin{array}{c}\text { Operating } \\
\text { Costs } \\
\text { Novel Panel }\end{array}$ & $\frac{\$ 0}{m^{2} \cdot y r}$ & $\frac{\$ 0}{m^{2} \cdot y r}$ & $\frac{\$ 2.80}{m^{2} \cdot y r}$ & $\frac{\$ 2.80}{m^{2} \cdot y r}$ \\
\hline $\begin{array}{c}\text { Operating } \\
\text { Costs } \\
\text { Concrete-based }\end{array}$ & $\frac{\$ 0.17}{m^{2} \cdot y r}$ & $\frac{\$ 0.01}{m^{2} \cdot y r}$ & $\frac{\$ 4.55}{m^{2} \cdot y r}$ & $\frac{\$ 4.74}{m^{2} \cdot y r}$ \\
\hline $\begin{array}{c}\text { GHG Emission } \\
\text { Novel Panel }\end{array}$ & $1 \mathrm{~kg}$ & $0 \mathrm{~kg}$ & $58 \mathrm{~kg}$ & $59 \mathrm{~kg}$ \\
\hline $\begin{array}{c}\text { GHG Emission } \\
\text { Concrete-based }\end{array}$ & $50 \mathrm{~kg}$ & $0 \mathrm{~kg}$ & $92 \mathrm{~kg}$ & $142 \mathrm{~kg}$ \\
\hline
\end{tabular}

For the heating dominant, cooling dominant, and neutral climatic conditions, significant cost-savings and GHG reduction were seen with the system comprising the novel radiant panel compared to the traditional concrete-based system. The magnitudes of these savings are a function of local utility rates for natural gas and electricity, the method of upstream energy generation method, and carbon-tax incentive; thus, the results will vary depending on a combination of these variables.

Overall, there were significant energy savings achieved with the use of the proposed radiant panel across all aforementioned scenarios. The reason why the proposed radiant panel achieves energy savings is because of its ability to respond quickly to fluctuations in heating and cooling demand. The operation with a concrete-based radiant system requires more reliance on a conventional heating and cooling system, which reduces energy savings, as witnessed through the energy 
simulation results. Also, because the proposed radiant panel is added on top of the typical floor construction, it minimizes heat transfer downward to the floor construction and ground below, due to its faster transfer of heat to the space above.

\section{Conclusions}

The first part of this study aimed at configuring the optimal radiant panel layout for a novel proposed design composed of a metal plate with spikes and flooring materials rendering it retrofittable and energy-efficient. Using an aluminium metal plate with 2.29 $\mathrm{mm}$ (0.09 in) long spikes nailed down to upper floor hardwood yielded an energy reduction of $63 \%$ compared to the base-case scenario of a configuration without the spikes, rendering them optimal in terms of energy-efficiency. Upon identifying the optimal configuration, comparisons were made between the traditional concrete-based radiant system and novel radiant panel under heating dominant, cooling dominant, and neutral climatic conditions. The novel panel demonstrated significant reduction in operating costs, GHG emission, and energy consumption. The metal spikes are engineered with a shape and material that is particularly effective at directing heat upward, towards the conditioned space. As a result, a smaller portion of the heat is conducted downward, and a smaller portion of the heat gets absorbed by the other materials. Also, since the panel is using high thermal conductivity material with fins, it responds quickly to fluctuations in thermal demands. These are the main reasons why energy savings were observed with the novel radiant panel. The magnitudes of these savings are expected to change with varying utility rates, use of renewable energy in the power plants, as well as government incentives for reduced energy consumption and GHG emissions reduction. 


\section{Acknowledgements}

The authors would like to thank the Natural Sciences and Engineering Research Council of Canada (NSERC) and Canada Research Chair (CRC) program for providing financial support. The authors also acknowledge technical expertise provided by Mr. John Swift from Nucap Industries Inc.

\section{Declaration of Interest Statement}

The industry partner provided suggestions to include realistic assumptions in the energy simulation model. This involvement had no bearing on the results of the study. The authors declare no conflicts of interest.

\section{References}

“ANSI/ASHRAE Standard 55-1992, Thermal Environmental Conditions for Human Occupancy." n.d.

“CEN (1994) EN 1264: Floor Heating - Systems and Components. European Committee for Standardization." n.d.

COMSOL. 2016. “COMSOL Multiphysics® Modeling Software.” Comsol. https://www.comsol.com/

Feustel, Helmut E., and Corina Stetiu. 1995. "Hydronic Radiant Cooling - Preliminary Assessment." Energy and Buildings. https://doi.org/10.1016/0378-7788(95)00922-K.

Ghaddar, Nesreen, Mohamad Salam, and Kamel Ghali. 2006. "Steady Thermal Comfort by Radiant Heat Transfer: The Impact of the Heater Position.” Heat Transfer Engineering. https://doi.org/10.1080/01457630600742480.

IEA. 2018. "Global Energy and CO2 Status Report.” Oecd/Iea.

International Energy Agency. n.d. "Energy Efficiency: Buildings.” Accessed December 2, 2018. https://www.iea.org/buildings/.

"International Organization for Standardization. Moderate Thermal Environments Moderate Thermal Environments - Determination of the PMV and PPD Index and Specification of the Conditions for Thermal Comfort, ISO 7730." 1994. Geneva. Izquierdo, M., and P. de Agustín-Camacho. 2015. "Solar Heating by Radiant Floor: 
Experimental Results and Emission Reduction Obtained with a Micro

Photovoltaic-Heat Pump System.” Applied Energy 147 (June): 297-307.

https://doi.org/10.1016/J.APENERGY.2015.03.007.

National Energy Board. 2017. “Canada’s Renewable Power Landscape 2017- Energy

Market Analysis."

National Energy Board. 2018. "Provincial and Territorial Energy Profiles-Canada."

Olesen, B. 2008. "Radiant Floor Cooling Systems." ASHRAE Journal 50 (9): 16.

Olesen, B. W. 2002. "Radiant Floor Heating in Theory and Practice." ASHRAE Journal 44 (7): 19.

Olesen, B. W., E. Mortensen, J. Thorshauge, and B Berg-Munch. 1980. “Thermal Comfort in a Room Heated by Different Methods." ASHRAE Journal.

Olesen, Bjarne W. 1997. "Possibilities and Limitations of Radiant Floor Cooling." In ASHRAE Transactions.

"Radiant Floor System, NUCAP Industries Inc." n.d. https:/www.gripmetal.com/nucap-energy/

Sakoi, Tomonori, Kazuyo Tsuzuki, Shinsuke Kato, Ryozo Ooka, Doosam Song, and Shengwei Zhu. 2007. "Thermal Comfort, Skin Temperature Distribution, and Sensible Heat Loss Distribution in the Sitting Posture in Various Asymmetric Radiant Fields." Building and Environment. https://doi.org/10.1016/j.buildenv.2006.10.050.

Simmonds, Peter, Stefan Holst, Stephanie Reuss, and Wayne Gaw. 2000. "Using Radiant Cooled Floors to Condition Large Spaces and Maintain Comfort Conditions." In ASHRAE Transactions.

TRNSYS. 2013. “Trnsys 17 - A Transient System Simulation Program.” Mathematical Reference, Solar Energy Laboratory, University of Wisconsin-Madison, USA.

Wisconsin-Madison, University of. 2010. "TRNSYS 17. Multizone Building Modeling with Type 56 and TRNBuild." TRNSYS Documentation.

Woodson, R. D. 2010. Radiant Floor Heating. 2nd ed. McGraw-Hill Education.

Workman, C. 2016. "Minister of Environmental and Climate Change Marks Canada's Ratification of the Paris Agreement." 
Zhang, Dongliang, Ning Cai, and Zijie Wang. 2013. "Experimental and Numerical Analysis of Lightweight Radiant Floor Heating System.” Energy and Buildings. https://doi.org/10.1016/j.enbuild.2013.02.016.

Zhang, Lian, and Baowen Cao. 2018. "Design and Analysis of a Floor Radiant Heating System Based on Energy Substitution Technology." Applied Sciences 8 (4). https://doi.org/10.3390/app8040491.

Zhang, Lun, Xiao Hua Liu, and Yi Jiang. 2012. "Simplified Calculation for Cooling/Heating Capacity, Surface Temperature Distribution of Radiant Floor.” Energy and Buildings. https://doi.org/10.1016/j.enbuild.2012.08.026.

Zhao, Kang, Xiao-Hua Liu, and Yi Jiang. 2013. “Application of Radiant Floor Cooling in a Large Open Space Building with High-Intensity Solar Radiation.” Energy and Buildings 66 (November): 246-57. https://doi.org/10.1016/J.ENBUILD.2013.07.014.

Zhao, Kang, Xiao Hua Liu, and Yi Jiang. 2016. "Application of Radiant Floor Cooling in Large Space Buildings - A Review.” Renewable and Sustainable Energy Reviews. https://doi.org/10.1016/j.rser.2015.11.028.

Zhou, Guobing, and Jing He. 2015. "Thermal Performance of a Radiant Floor Heating System with Different Heat Storage Materials and Heating Pipes." Applied Energy. https://doi.org/10.1016/j.apenergy.2014.10.058. 